\title{
Aquaculture Applications of the Family Blenniidae ${ }^{1}$
}

\author{
Jesse Von Linden, Joshua T. Patterson, Cortney L. Ohs, and Matthew A. DiMaggio²
}

Blennies are a popular family of fishes among marine aquarium hobbyists. These hardy fish are small, colorful, and rarely aggressive to other reef species, making them a great choice for beginning aquarists. The Blenniidae family is particularly popular in the reef-keeping community. Blenniidae are valued for their active nature and distinct behaviors such as substrate cleaning and algae eating. According to a 2012 report on marine ornamental fish, the family Blenniidae is the 11th most imported group into the United States, by volume, with over 75 distinct species being traded (Rhyne et al. 2012). Due to this popularity, many species of blennies are currently cultured and sold worldwide, with additional research underway to bring new species to market. This publication highlights culture methods for members of the Blenniidae family and briefly covers description and taxonomy, natural history, diseases, and marketing. This document will provide valuable information both to potential producers looking to expand into marine ornamental species and to members of the general public.

\section{Description and Taxonomy}

The family Blenniidae is comprised of two subfamilies with almost 400 species in total. These fish are generally found in marine environments and benthically oriented. They are scaleless, slender, and usually small, with a length ranging from 50 to $140 \mathrm{~mm}$. Sexual dimorphism in size and color is seen in some species of blennies. Males may become more colorful during the spawning season, and these colors are most pronounced near their head and jaw areas. Coloration can vary between earthy and sandy tones to more vibrant colors like red and orange. Coloration patterns may include vertical stripes or streaks along with dots and circular blotches. Blennies have rounded but somewhat compressed heads with large eyes. A dorsal fin runs the length of the body with small ventral fins under the blunt head. These omnivorous fish have a single row of comblike teeth they use to remove algae, detritus, and small invertebrates from the sea bottom. They have been observed nipping fish as well. In captivity, these fish will eat commercial diets that sink to the bottom of the tank. Another interesting feature of this family is that members of the poison fang blennies (Meiacanthus spp.) have venom-producing glands that they use to prevent predation. Several species of blenny are commercially produced (Table 1). The most prominent genus of these is Meiacanthus. Other popular genera cultured or traded in the industry include Ecsenius spp. and Salarias spp. These will be referred to as a collective group known as blennies throughout the rest of the paper.

1. This document is FA225, one of a series of the Program in Fisheries and Aquatic Sciences, School of Forest Resources and Conservation, UF/IFAS Extension. Original publication date May 2020. Visit the EDIS website at https://edis.ifas.ufl.edu for the currently supported version of this publication.

2. Jesse Von Linden, graduate student, Program in Fisheries and Aquatic Sciences, School of Forest Resources and Conservation; Joshua T. Patterson, assistant professor, Program in Fisheries and Aquatic Sciences, School of Forest Resources and Conservation, UF/IFAS Extension and Florida Sea Grant, The Florida Aquarium's Center for Conservation; Cortney L. Ohs, associate professor, Indian River Research and Education Center, Program in Fisheries and Aquatic Sciences, School of Forest Resources and Conservation, UF/IFAS Extension and Florida Sea Grant; Matthew A. DiMaggio, assistant professor, Tropical Aquaculture Laboratory, Program in Fisheries and Aquatic Sciences, School of Forest Resources and Conservation, UF/IFAS Extension and Florida Sea Grant.

The Institute of Food and Agricultural Sciences (IFAS) is an Equal Opportunity Institution authorized to provide research, educational information and other services

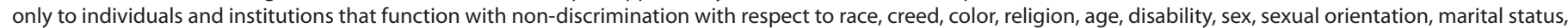

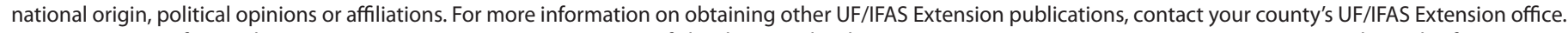
U.S. Department of Agriculture, UF/IFAS Extension Service, University of Florida, IFAS, Florida A \& M University Cooperative Extension Program, and Boards of County Commissioners Cooperating. Nick T. Place, dean for UF/IFAS Extension. 


\section{Natural History}

\section{Range and Habitat}

Blennies have been found worldwide across a broad range of temperatures and salinities. The most popular species found in marine aquariums come from the tropical waters of the Pacific and Indian Oceans. These fish generally inhabit seagrass beds, tide pools, or lagoons. These types of shallow-water environments are easily reproduced in aquaculture settings. Being exposed to fluctuating tides also makes blennies hardy and capable of surviving changes in water chemistry and flow. Blennies will usually create a den in the sand or amongst rock crevices. In natural settings, blennies depend on foraging for algae and detritus from their surrounding habitat. Den selection is important for these fish because they do not spend a lot of time swimming, and thus food resources need to be close by.

\section{Reproduction and Early Life History}

Blennies exhibit an array of reproductive strategies. It is not currently known whether certain genera of blennies are capable of changing sex (hermaphroditic) or whether they maintain one sex for their entire lives (gonochoristic). Contrasting reports have not been substantiated. Social polygyny, in which a male mates with multiple females, has been noted in blennies. Larger males with more desirable dens are able to court and mate with the largest number of females. Females are demersal egg layers, meaning they spawn sinking eggs that stick to substrate. They will usually position their clutch in the safety of the male's den. The male will stay with the eggs until they hatch and is sometimes joined by the female. The spawning process can take just hours or last a whole day, and males become very active during this time, protecting their dens from predators and rivals. When hatching begins, the male can be seen using his fins to help the larvae emerge from the eggs. Larvae will receive no more parental care once this process is complete. Hatch time after spawning is generally 6 to 7 days. Post hatch larvae are precocial, meaning they have developed eyes and are capable of hunting for food. At 10 to 15 days post hatch (DPH), fins develop and the primitive vertebral column begins to bend dorsally (notochord flexion). During this stage, the larvae float in the water column eating small planktonic organisms, and their bodies begin to metamorphose into the juvenile form. Once this transition occurs, juvenile blennies sink to the ocean floor and look for a den in the surrounding reef area. The timing of this transition is different for each species but generally takes place anywhere from 26 to $35 \mathrm{DPH}$. Lengths of the fish at settlement can vary by species and sex, but in general, fish are 11 to $13 \mathrm{~mm}$ when "settling" behavior begins (Calado et al. 2017).

\section{Culture Techniques \\ Systems}

A variety of recirculating systems are used when culturing the range of blenny life stages. Regardless of its design, a system must have appropriate filtration to maintain acceptable water quality because water exchange is limited. Recirculating systems should use both mechanical and biological filtration to remove waste materials from the water. Ultraviolet sterilization or ozone can also be used to help reduce the occurrence of bacteria, parasites, and other organisms. General water chemistry guidelines are as follows: temperature $25^{\circ} \mathrm{C}$ to $28^{\circ} \mathrm{C}, \mathrm{pH} 8.2$ to 8.4 , and salinity $\sim 33 \mathrm{mg} / \mathrm{L}$. Lastly, water flow should be maintained at a high enough rate to allow for proper oxygenation and waste removal. These flow rates will vary depending on the volume of the culture system along with the stocking density and feeding rates. SRAC Publication No. 0451 and SRAC Publication No. 0452 are excellent resources for further information on recirculating system design and operation.

\section{Broodstock and Spawning}

Like many hermaphroditic marine ornamental fish, some species of blennies are thought to be able to change sexes if necessary. One way to form "mated pairs" is by creating small groups of juveniles and allowing them to couple on their own. During this time, fish should be closely observed for aggressive behavior and separated if necessary. Once pairs are formed, they should be placed into individual 40 - to $80-\mathrm{L}$ tanks for spawning. The tanks should have nothing on the bottom, and if there are neighboring tanks or excess activity surrounding the tank, three sides should be obstructed or painted with an opaque material to reduce stressors on the fish while spawning. A commercial broodstock facility is depicted in Figure 1. Any other material in the tank should be limited to what is necessary for the blennies to spawn in. Objects like clay flower pots, empty oyster shells, and PVC pipe can be used. The spawning structure may double as a den for the blennies. During this process, the male and female may rub against one another and then enter the den where the females will lay their eggs. In striped blennies (Meiacanthus grammistes), the first spawns can take months to occur and may result in small clutch sizes and/or poor-quality larvae (Calado et al. 2017). Large, mature females can produce 150 to 200 eggs at one time (Olivotto et al. 2010). Once the first cycle of spawning is completed, spawns can occur as frequently 
as every 8 days throughout the year. Parental care of egg clutches is evidenced in many blenny species, and removing the parents shortly after the clutch has been laid may result in loss of eggs to disease or decreased hatch rate (Calado et al. 2017).

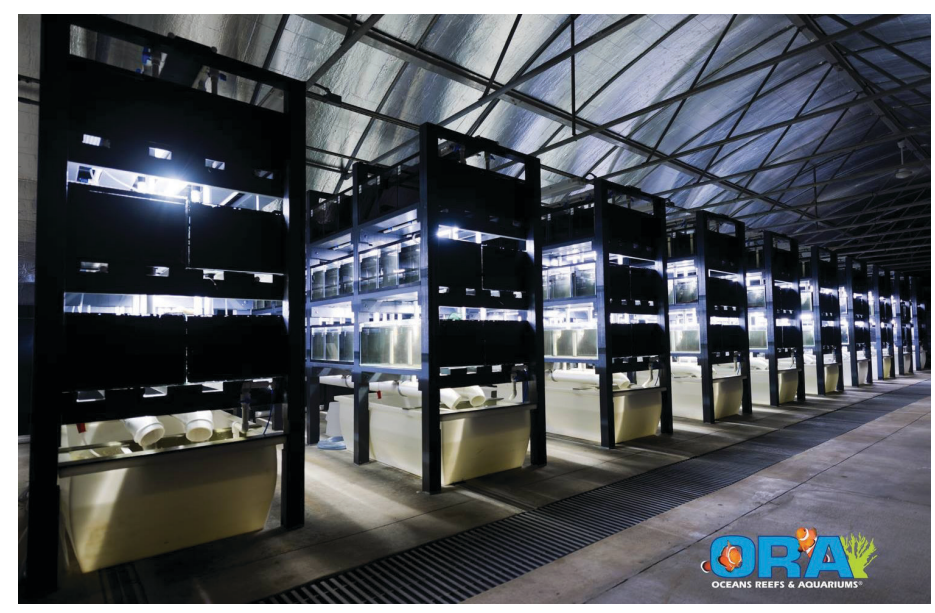

Figure 1. Large commercial broodstock setup at ORA.

Credits: Photos used with permission from Oceans Reefs and Aquariums (ORA) (Ft. Pierce, FL).

A suitable broodstock diet is essential to long-term reproductive success and high-quality egg clutches. Blennies are omnivorous, so creating a balanced diet of algae, in addition to protein-rich feeds (more than $40 \%$ protein), is important. One option is to offer a blended diet of commercially premade food in a paste, pellet, or flake form until the fish are satiated. In addition to these foods, supplemental feedings of fish eggs, mysis shrimp (Mysis sp.), and vitaminenriched plant matter should also be offered. Fish feed can be one of the most expensive parts of the culture process, but good nutrition is important for proper conditioning and reproduction.

\section{Eggs and Larvae}

Eggs from quality broodstock are round or oval and slightly flattened where they are adhered to the substrate. They are yellow to orange when first laid and relatively small, about $1 \mathrm{~mm}$ across. Incubation time is species- and temperature-dependent, but 7 to 11 days is common. As embryos develop in the eggs, the color changes to grey and the eyes become visible. Before hatch, the embryos may be seen inside the egg moving and flicking their tails. The eyes, heart, and yolk sack should all be visible at this point. Before the eggs hatch, it should be determined whether the larvae will be left in the tank or removed to hatch in a separate tank from their parents.

Eggs incubated in the parent tank may exhibit increased hatch rates and decreased disease incidence due to parental care. Removing the eggs just before hatch reduces chances of larval predation by the broodstock and mortalities associated with transferring larvae or losses to filtration. Hatching generally occurs within the day once eggs become clear and more oval in shape, and once the embryo can be seen moving inside. Use care when removing the eggs and the substrate; the parents can become aggressive towards anything getting near the clutch and could bite or otherwise damage eggs. Once the eggs are removed, replace the substrate with a new one so that the parents have a shelter and a new place to start their spawning cycle over again. When the eggs are placed in the larval grow-out tanks, a low and continuous flow should move over them, mimicking their parents' finning action. This can be duplicated using a small pump. If timed properly, the eggs should hatch soon after removal from the broodstock tank.

Larval grow-out tanks should be larger than the broodstock tanks because there will be higher densities of fish and feed in these systems. Sizes and shapes of tanks can be chosen to suit the available space and production goals. A preferred set up would be an opaque circular tank (40 to $200 \mathrm{~L}$ ) with adjustable flow and aeration settings within a recirculating system using a 12 light : 12 dark photoperiod. Mesh coverings 250 to $1000 \mu \mathrm{m}$ in size over the drains and standpipes should be used so that no larvae are flushed out of the system, but uneaten feeds can exit.

Post hatch these fish are about 1.5 to $6.5 \mathrm{~mm}$ long. Like many precocial species, they are born ready to feed with working jaws, pigmented eyes, and a small yolk sack reserve. This gives them the ability to swim and feed early on in their life cycle. The yolk reserve is normally depleted after 3 days, and live food will need to be provided thereafter. For the first feeding enriched rotifers (Brachionus plicatilis or B. rotundiformis) should be used and can be continued for the first 3 to 10 DPH (Calado et al. 2017). Including live microalgae in the larval tanks for "greenwater" culture has several benefits, among them increased enrichment of live feeds and increased prey capture success (Calado et al. 2017). Using smaller, more frequent feedings instead of larger feedings is recommended because it allows the blennies to feed on the rotifers before they metabolize the enrichment. By the end of the first seven days, larvae should be transitioned from rotifers to brine shrimp (Artemia sp.) (Moorhead and Zeng 2011). Weaning larvae from rotifers to brine shrimp should be done slowly, avoiding abrupt transitions in feeds. As the larvae continue to grow, commercial larval feed can be introduced, starting with small microparticulates and working upwards in size as they grow. As the particle size increases, live feeds should be removed from the daily feeding regimen. Since many 
species of blennies are omnivorous, finding a commercial feed with an appropriate composition is important. As the larvae progress, developmental milestones will be speciesspecific in their timing. Below are some specific examples of popular blennies in marine culture and different milestones the larvae will reach throughout development.

For poison fang blennies (Meiacanthus spp.), at 10 to 15 $\mathrm{DPH}$ fin rays will develop, notochord flexion will begin, and length should be about 4.7 to $5.5 \mathrm{~mm}$. From 25 to 35 DPH settlement will have occurred, most of the larvae will begin to associate with the bottom of the tank, and larval lengths may reach about 8.2 to $13.3 \mathrm{~mm}$. At $35 \mathrm{DPH}$ adult coloration may be seen along with the distinctive forked tail the group is known for (Calado et al. 2017; Moorhead and Zeng 2011). For combtooth blennies (Salarias spp.), notochord flexion begins at a length of 4 to $14 \mathrm{~mm}$ and they will settle out of the water column to the bottom of the tank at about 10 to $25 \mathrm{~mm}$. This process generally begins around $14 \mathrm{DPH}$.

\section{Growout}

Intensive culture is common in most marine ornamental aquaculture species. Blennies can be moved out of the larval grow-out tanks after they have passed the metamorphosis stage and settled to the tank bottom. Stocking densities of tanks should be matched to the size of the tank and the quality of the filtration system. Water quality should be maintained and high-quality food that is rich in protein mixed with algae should be provided. Feeding 2 to 3 times a day is not uncommon, as long as all juveniles are satiated. Following these protocols will increase the number of marketable young at the end of the aquaculture process. After the first month post hatch, growth rates and sizes will become increasingly variable among blenny genera. Sexual maturity will also vary among species. Some blennies become sexually mature at around $20 \mathrm{~mm}$ in length and are ready for commercial sale soon after (Ditty et al. 2005). Most blennies are sold commercially at sizes between about 25 and $50 \mathrm{~mm}$.

\section{Disease}

A collection of different diseases stemming from bacteria, viruses, fungi, and single-celled or multi-cellular parasites can afflict marine fish. In aquaculture, pathogens can spread through recirculating systems quickly if the proper biosecurity and management protocols are not followed. Implementation of quarantine and biosecurity protocols will help reduce the possibility of outbreaks in a facility. Quarantining new fish before they enter the larger breeding system and keeping low fish densities in tanks can help reduce stress and the chance of diseases being introduced to closed systems. Using UV sterilization and ozone as part of an aquaculture filtration system can also reduce the severity of an outbreak if diseases occur. Specific examples of common marine fish diseases are Cryptocaryon irritans and Amyloodinium ocellatum. Symptoms exhibited by fish with these diseases include but are not limited to the following: lethargy, loss of appetite, increased respiration, and "white spots" or nodules on the skin. Fish may also be seen "flashing" or rubbing themselves against the tank walls or rocks in the tank. C. irritans is a ciliated protozoan while A. ocellatum is a dinoflagellate protozoan. Further information on identification and treatment of these diseases is presented in Yanong (2012) and Francis-Floyd and Floyd (2011). Always consult a veterinarian or specialist when diagnosing and treating sick fish.

\section{Marketing and Economics}

With the advent of the internet and improved shipping methods that decrease the mortality of fish in transit, larger numbers of ornamental marine fish are coming into the United States every year. Of the approximately 4,000 naturally occurring coral reef fish species, over half are being imported to countries around the globe, mostly from the South Pacific. The family Blenniidae is just outside of the top ten most popular marine fish traded, with 77 different species occurring in the marine ornamental hobby (Rhyne et al. 2012). With so many species of fish being traded, research into developing sustainable methods of culturing and marketing these fish has increased.

Several genera of blennies have already been cultured with the most predominant being poison fang blennies ( $M e i-$ acanthus spp). As of 2019, up to 10 unique species are being commercially cultured. Aquacultured species that have been raised in captivity may be more willing to accept artificial diets and fare better than wild-caught counterparts. Certain species of blennies are already retailing for $\$ 30.00$ to $\$ 50.00$ each, depending on the supply and size. However, wholesale prices can be considerably lower depending on quantities and the distance the fish are shipped. The aquaculture market represents a unique opportunity with great potential for growth. As more research is completed on ways to increase efficiency and culture novel species, the availability of cultured blennies in the marketplace should become more commonplace. 


\section{Conclusions}

As a popular family of fish in the marine ornamental trade, many species of blennies are already being aquacultured for mass markets. Known as an entertaining fish, blennies add a lot of personality to an aquarium. The small body size of most blennies makes them great for aquarists with small starter aquariums and anyone searching for fish that can be added to established tank communities. As more time and resources are devoted to optimizing aquaculture methods of blenny species, substantial gains in efficiency and diversity of species in culture should be realized. Further research will ensure blennies will continue as a staple of the marine ornamental aquaculture industry with other popular fish like clownfish and gobies.

\section{Suggested Readings}

SRAC Publication No. 0451, Recirculating Aquaculture Tank Production Systems: An Overview of Critical Considerations

SRAC Publication No. 0452, Recirculating Aquaculture Tank Production Systems: Management of Recirculating Systems

SRAC Publication No. 0701, Culture of Small Zooplankters for the Feeding of Larval Fish

SRAC Publication No. 0702, Artemia Production for Marine Larval Fish Culture

SRAC Publication No. 5004, Phytoplankton Culture for Aquaculture Feed

All publications available at https://srac.tamu.edu/.

\section{Sources}

Calado, Ricardo, et al. 2017. Marine Ornamental Species Aquaculture. Hoboken, NJ: Wiley Blackwell.

DiMaggio, Mathew A., et al. 2017. "Species Profile: Clownfish." Southern Regional Aquaculture Center Publication No. 7213. 1-7.

Ditty, J. G., et al. 2005. "Larval Development of Five Species of Blenny (Teleostei: Blenniidae) from the Western Central North Atlantic, with a Synopsis of Blennioid Family Characters." Journal of Fish Biology 66(5): 1261-1284. doi:10.1111/j.0022-1112.2005.00675.x.
Francis-Floyd, Ruth, and Maxine Floyd. 2011. "Amyloodinium ocellatum, an Important Parasite of Cultured Marine Fish." Southern Regional Aquaculture Center Publication No. 4705. 1-12.

Moorhead, Jonathan A., and Chaoshu Zeng. 2011. "Breeding of the Forktail Blenny Meiacanthus atrodorsalis: Broodstock Management and Larval Rearing." Aquaculture 318(1-2): 248-252. doi:10.1016/j.aquaculture.2011.05.018.

Olivotto, Ike, et al. 2020. "Feeding Strategies for Striped Blenny Meiacanthus grammistes Larvae." Aquaculture Research 41(9). doi:10.1111/j.1365-2109.2010.02531.x.

Rhyne, Andrew L., et al. 2012. "Revealing the Appetite of the Marine Aquarium Fish Trade: The Volume and Biodiversity of Fish Imported into the United States." PLoS ONE 7(5). doi:10.1371/journal.pone.0035808.

Yanong, R.P.E. 2012. Cryptocaryon irritans Infections (Marine White Spot Disease) in Fish. FA164. Gainesville: University of Florida Institute of Food and Agricultural Sciences. https://edis.ifas.ufl.edu/fa164 
Table 1. Blenny species currently being cultured for the marine ornamental hobby. Photos used with permission from Oceans Reefs and Aquariums (ORA) (Ft. Pierce, FL) and Proaquatix (Vero Beach, FL).

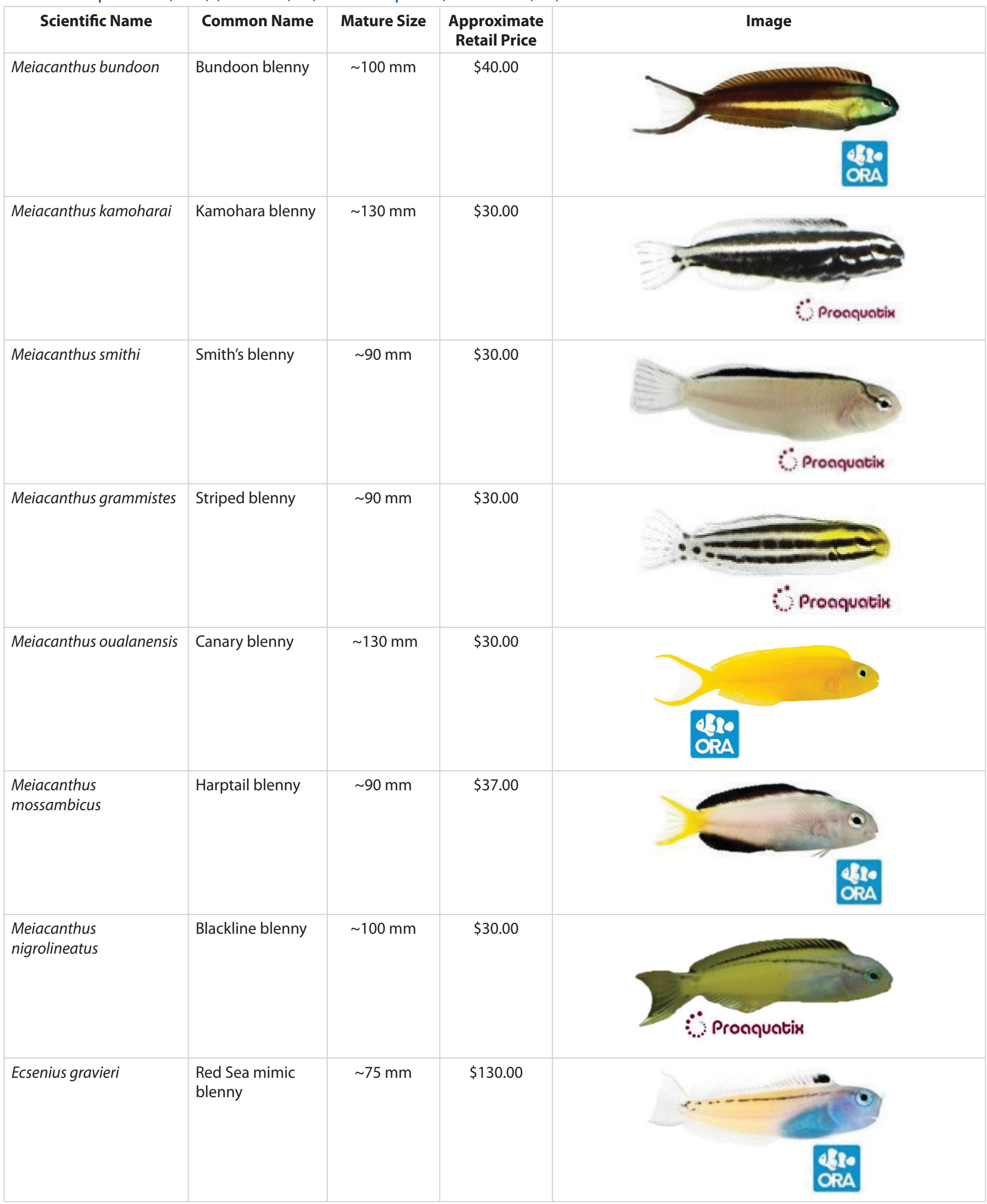

